\title{
1 Anatomy of the heart of the leatherback turtle
}

2

3 Short title: turtle heart

4

5 Bjarke Jensen ${ }^{\mathrm{a},{ }^{*}}$, Henrik Lauridsen $^{\mathrm{b}}{ }^{\text {, Grahame } \mathrm{Webb}^{\mathrm{c}} \text {, Tobias Wang }}{ }^{\mathrm{d}}$

6

$7 \quad{ }^{a}$ Department of Medical Biology, Amsterdam Cardiovascular Sciences, Amsterdam University

8 Medical Centres, Amsterdam, The Netherlands.

9 b Department of Clinical Medicine, Aarhus University, Palle Juul-Jensens Boulevard 99, 8200, 10 Aarhus N, Denmark.

$11{ }^{\mathrm{c}}$ Wildlife Management International, PO Box 530 Karama, NT, 0813 Australia; and Research 12 Institute for the Environment and Livelihoods, Charles Darwin University, Darwin, NT, 0909 13 Australia.

$14{ }^{\mathrm{d}}$ Department of Biology-Zoophysiology, Aarhus University, Aarhus C, Denmark. 15

16 *corresponding author:

17 Bjarke Jensen, Ph.D.

18 Amsterdam UMC

19 Department of Medical Biology

20 Room L2-106

21 Meibergdreef 15

22 1105AZ Amsterdam

23 The Netherlands

24 Phone: +31 205664659

25 Fax: not available

26 Mobile: +31626450696

27 email: b.jensen@amsterdamumc.nl

28 ORCID: 0000-0002-7750-8035 


\section{Abstract}

30 Non-crocodylian reptiles have hearts with a single ventricle, which is partially separated by a muscular ridge that provide some separation of blood flows. An exceptional situation exists in monitor lizards and pythons, where the ventricular left side generates a much higher systolic blood pressure than the right side, thus resembling mammals and birds. This functional division of the ventricle depends on a large muscular ridge and may relate to high metabolic demand. The large leatherback turtle $(<1000 \mathrm{~kg})$, with its active ocean-going lifestyle and elevated body temperatures, may have similar adaptations. Here, we report on the anatomy the hearts of two

37 leatherback turtles. One stranded in Ballum, Denmark in 2020, and was examined in detail, supplemented by observations and photos of an additional stranding specimen from Canada.

39 The external morphology of the leatherback heart resembles that of other turtles, but it is large.

40 We made morphometric measurements of the Ballum heart and created an interactive 3D model using high resolution MRI. The volume of the ventricle was $950 \mathrm{ml}$, from a turtle of 300

$42 \mathrm{~kg}$, which is almost twice as large as in other reptiles. The Ballum heart was compared to MRI

43 scans of the hearts of a tortoise, a python, and a monitor lizard. Internally, the leatherback heart

44 is typical of non-crocodylian reptiles, and did not contain the well-developed septation found 45 in pythons and monitor lizards. We conclude that if leatherback turtles have exceptional circulation needs, they are sustained with a relatively large but otherwise typical noncrocodylian reptile heart. 


\section{Introduction}

The septation of the cardiac ventricle in non-avian reptiles is much more variable than in other vertebrate groups (Poelmann \& Gittenberger-de Groot, 2019; Jensen \& Christoffels, 2020), and this variation may well shed light on the evolution of the two ventricles in mammals and birds, which both evolved from an ancestor with a single ventricle (Kardong, 2006; Jensen et al., 2010a; Poelmann et al., 2014; Katano et al., 2019).

Brücke (1852) first established the heart of non-crocodylian reptiles consists of two atria and a single ventricle (Brücke, 1852; Webb, 1979). Later studies clarified that reptiles have an additional chamber because the venous sac behind the right atrium, the sinus venosus, contracts well before the atria and aids the filling of the right atrium (Johansen, 1959; Valentinuzzi \& Hoff 1972; Jensen et al., 2017). Brücke also established that the single ventricle is partially septated into three major compartments: i) The right-most is the cavum pulmonale that leads to pulmonary artery (see label ' $\mathrm{CP}$ ' in Figure 1), ii) The left-most compartment (cavum arteriosum, CA), which receives the inflow from the left atrium, and iii) the smaller cavum venosum, situated between the $\mathrm{CP}$ and the $\mathrm{CA}$, that receives the inflow from the right atrium. Two bi-leaflet valves guard the outflows into the left and right aortas in the cranial part of cavum venosum, and oxygen-rich blood from the left-situated cavum arteriosum therefore must pass the through the cavum venosum during cardiac systole before being ejected into the systemic arteries. The right-situated cavum pulmonale receives blood from the right atrium in diastole, which also passes through the cavum venosum. The cavum venosum is thus a crossroad of filling in diastole and ejection in systole, and hence an important site of intracardiac shunting (Hicks, 1998; Burggren et al., 2020).

The cavum venosum is small in monitor lizards and particularly in pythons (Webb et al., 1971; Jensen et al., 2014). This reflects, at least in part, that the ventricular muscle underneath the atrioventricular valve is particularly prominent. This structure, which separates the cavum arteriosum from the cavum venosum, is called the vertical septum. A second septum, called the muscular ridge, is also more developed in monitors and pythons than in other reptiles, and further confine the volume of the cavum venosum. Finally, across from the muscular ridge is the bulbuslamelle (Greil, 1903), which is so developed in monitors and pythons that it together with the muscular ridge, can form a pressure-tight seal in systole. This shields the low pressure of the cavum pulmonale and pulmonary circulation from the almost mammal-like higher pressure generated in the cavum arteriosum and cavum venosum (White, 1968; Burggren \& Johansen, 1982; Wang et al., 2003; Jensen et al., 2010a). The presence of this substantial 
septation is revealed on the ventricular surface by the presence of large coronary vessels, similar to the setting in crocodylians, birds, and mammals (Jensen et al., 2014).

Not much is known of the cardiac anatomy and physiology of the leatherback sea turtle (Dermochelys coriacea). The most detailed anatomical study is more than a century old (O’Donoghue, 1918) and reports that the leatherback heart is configured much like other reptile hearts (O'Donoghue, 1918). The external appearance is also much akin to other chelonians (Wyneken, 2001) (Figure 1). Later, Adams (1962) reported large foramens between the major arteries in a single stranded leatherback. Adams (1962) also described numerous dimples, or under-developed foramens, on the luminal side of these vessels, and speculated that the foramens are a common feature of the leatherback heart. The leatherback ventricle has also been noted as having "an exceptionally well-developed muscular ridge" (Wyneken, 2009), although no visual or other supporting evidence was provided. Thus, the degree to which the muscular ridge compares with well-developed one of monitors and pythons is unclear. When these observations are considered in relation to the large body size, the capacity for long oceanic migrations, and the ability to maintain a body temperature several degrees higher than the surrounding sea water (Paladino et al., 1990; James \& Mrosovsky, 2004), leatherbacks may be another reptile in which the ventricle has adapted to better exploit pressure separation.

Here we undertook an anatomical study of the hearts of two large leatherback turtles to assess whether the leatherback heart is typical of chelonians or has features similar to monitors and pythons. Should the latter be the case, it is likely that the leatherback ventricle has pressure separation which is considered a prerequisite for high metabolic rates (Quick \& Ruben, 2009; Lovegrove, 2019; Grigg et al., 2021).

\section{Materials and Methods}

\section{Animals}

The reported findings are mostly based on the heart of the leatherback that stranded near Ballum (Denmark) on $3^{\text {rd }}$ of November 2020. It had a curved carapace length of $148 \mathrm{~cm}$ and was estimated to weigh $300 \mathrm{~kg}$. It was brought to The Fisheries and Maritime Museum in Esbjerg, Denmark, given the specimen ID “R2117", and kept frozen until its dissection on $6^{\text {th }}$ of August 2021. The other heart examined came from a stranded leatherback in Canada (2009), which was examined in Australia, mainly to confirm the foramen between the arterial and pulmonary arteries described by Adams (1962). Photos taken during the dissection (Sept 2011) allowed verification of observations made on the Ballum heart. It is stated explicitly in the 
116 Results when findings on the Ballum heart could be verified in the Canadian heart.

117 Comparisons are made between images from MRI of hearts of a Geochelone tortoise and a

118 Burmese python (adapted from Jensen et al., 2014) as well as an Asian water monitor lizard

119 (adapted from Hanemaaijer et al., 2019).

120

121 Dissection and fixation

122 The Ballum heart was dissected free and all major structures were more or less intact.

123 Accordingly, the dissected tissue included parts of the major arteries, esophagus, and the left

124 lung, together with coagulated blood, and weighed in total $11.2 \mathrm{~kg}$. This specimen was kept in

125 a 251 bucket filled with 4\% formaldehyde buffered to $\mathrm{pH}$ 7.4. The formaldehyde was renewed

126 after three days and total immersion fixation time was one week. After this, the heart was

127 transferred to a phosphate buffered saline and washed twice for three days to remove residual

128 formaldehyde in preparation for magnetic resonance and $\mathrm{x}$-ray computed tomography imaging

129 (MRI and CT).

130

Magnetic resonance and $x$-ray computed tomography imaging and $3 D$ reconstruction

132 Magnetic resonance imaging (MRI) was performed on an Siemens Magnetom Skyra system equipped with a Flex Large 4 surface coil using a T2-weighted 3D sequence with the following parameters: field strength $=3 \mathrm{~T}$, repetition time $=1000 \mathrm{~ms}$, echo time $=132 \mathrm{~ms}$, flip angle $=$ $120^{\circ}$, field-of-view $=288 \times 288 \times 160 \mathrm{~mm}^{3}$, spatial resolution $0.5 \mathrm{~mm}$ isotropic, number of averages $=4$, acquisition time $=3.7 \mathrm{~h}$.

X-ray computed tomography (CT) was performed using a Toshiba Aquillon Prime SP system with the following parameters: $\mathrm{x}$-ray tube voltage $=120 \mathrm{kVp}$, $\mathrm{x}$-ray tube current $=250$ $\mathrm{mA}$, integration time $=1000 \mathrm{~ms}$, field-of-view $=410.1 \times 410.1 \times 404.0 \mathrm{~mm}^{3}$, spatial resolution

$140=0.8 \mathrm{~mm}$ isotropic, convolution kernel $=\mathrm{FC} 18$, acquisition time $=90 \mathrm{~s}$.

141 The MRI and CT generated image stacks were imported to the 3D software Amira 142 (version 3D 2021.2, FEI SAS, Thermo Fisher Scientific). Labeling of structures were done in 143 the Segmentation Editor module. The volumes of labelled structures were retrieved using the 144 Materials Statistics module. Distances were measured in Orthographic view using the Measure 145 Line tool on either images of the image stack or on a volume rendering of the label file. The 146 Amira model was converted to an interactive 3D pdf as previously described (de Bakker et al., 147 2016). 
Results

150 Figure 2A shows the ventral side of the heart in situ of the Ballum leatherback. The coloration of the ventricle suggested that the tissue had not decomposed to any great extent. Numerous coronary vessels were found on the ventricular surface, but not in a similar configuration as in pythons, monitors and crocodylians, where the major coronary vessels run along the surface of major septation. Overall, the proportions and shapes of the cardiac chambers corresponded well to the previous accounts of leatherback hearts. A pronounced guberculum cordis extended from the ventricular apex. Figure 2B exemplifies one of the MR generated images. Larger structures such as the atrial septum can be identified. Numerous straight lines were observed in the cavities of the chambers and vessels on both MRI and CT images. We suspect these lines reflect structured coagulation of the red blood cells and they were not perceived as tissue. Also, thick somewhat concentric bands are seen in the ventricular muscle. These bands were not obvious on CT (Fig. 2B), which suggest that they do not reflect substantial differences in tissue density and we believe they are artefacts of fixation. From the MRI image stack, we reconstructed the chambers, valves at the chamber junctions, and the major arteries (Fig. 2C). The interactive pdf of this model, in which each labelled structure can be made visible or transparent, can be found in the supplement (Supplementary Figure 1). The ventricular wall (including septums), which was the best demarcated wall of the four chambers, comprised $950 \mathrm{ml}$. Concerning the atria, the atrial septum was $29 \mathrm{ml}$, the right atrial wall was $289 \mathrm{ml}$, and the left atrial wall was $125 \mathrm{ml}$. The wall of the sinus venosus was extremely faint in many images and it could not be reconstructed such that the tissue volume could be estimated. The estimated ventricular index of $0.33 \%(950 \mathrm{ml} / 300 \mathrm{~kg})$ is quite high for a reptile where the average ventricular index is approximately $0.2 \%$ (Jensen et al 2014). The superficial appearance of the leatherback heart is typically chelonian and it resembles less that of the squamate monitors and pythons (Fig. 2C).

The three sinus horns became confluent dorsal to the sinuatrial junction (Fig. 2C). While the sinuatrial junction was not wide in proportion to the right atrium, it was still well beyond 2 $\mathrm{cm}$ in width (Fig. 3A). The junction was guarded by two leaflets as is typical in reptiles (Fig. 3A). A large right leaflet and a smaller left leaflet guarded the right and left atrioventricular opening respectively. These leaflets were merged medially to each other and to the atrial septum, as is typical in non-crocodylian reptiles (Fig. 3B). The right and left atrioventricular openings were dorsal and to the left of the aortas. In the Canadian specimen, when the apical region of the ventricle had been resected, a similar atrioventricular valve was found (Fig. 3C- 
D). No pronounced septation was found under the atrioventricular valve of the Canadian heart

182

183

184

185

186

187

188

189

190

191

192

193

194

195

196

197

198

199

200

201

202

203

204

205

206

207

208

209

210

211

212 (Fig. 3D).

Images from MR revealed the absence of pronounced septation under the atrioventricular valve in the Ballum heart (Fig. 4A). Dorsally and ventrally, the atrioventricular valve was embedded in ventricular myocardium, as is typical in non-crocodylian reptiles (Fig. 4B). In this way, both the Ballum and Canadian hearts resembled the heart of other chelonians (Fig. 4C). The ventricular muscle in monitors and pythons, on the other hand, reaches much closer to the atrioventricular valve and is referred to as the vertical septum (Fig. 4D-E).

The most pronounced septation of the Ballum ventricle was the muscular ridge (Fig. 5A). It harbors the base of the ventral leaflet of the valve of the left and right aorta and the dorsal leaflet of the pulmonary artery. Opposite to it is the bulbuslamelle, which harbors the dorsal leaflet of the valve of the left and right aorta. As is typical of non-crocodylian hearts, the muscular ridge is close to the horizontal plane near the arterial valves (Fig. 5A). It then has a helical course towards the apex, such that its free margin makes contact to do the dorsal-right wall of the ventricle (Fig. 5B). At least in the Canadian heart, there was a substantial space between the free edge of the muscular ridge and the opposite wall (Fig. 5C). This configuration is similar to that of the tortoise (Fig. 5D), and does not resemble the python or monitor hearts where the muscular ridge is much larger (Fig. 5D-E). It is not unusual for reptiles and turtles in particular to have a substantial cartilaginous deposit where the muscular ridge merges with the truncus (Poelmann et al., 2017) but we could not detect such deposit on the CT or MRI (data not shown). The bulbuslamelle is also very developed in monitors and pythons, but this is best appreciated in ventricles that are not fully contracted, such as in the python heart depicted in Figure 5F. Notice that in the python heart, there is only a narrow gap between the muscular ridge and the bulbuslamelle even in the dilated state, which is in contrast to that of chelonians (Fig. 5C-D). Due to the state of contraction in the Ballum heart, however, we could not assess whether the bulbuslamelle was typical or more like that of monitors and pythons.

A single truncus arteriosus harbored the left and right aorta and the pulmonary artery in the specimens from Ballum and Canadian, as is typical in reptiles (Figs. 2C,3C). In the Ballum heart, we surveyed the entire truncus in three planes for foramens between the major arteries. Only one potential foramen was found (Fig. 6). It was found in the shared wall of the left and right aorta, but even if it was patent it was tiny. The entire truncus was dissected in the Canadian heart without any foramen or large dimples being identified in or between any vessels. 
Discussion

215 Our assessment indicates that the leatherback turtle heart resemble that of other chelonians and

216 does not exhibit obvious specializations for functional separation of the ventricle as it has been demonstrated in monitors and pythons. Overall, our description supports O'Donoghue's original conclusion that the leatherback heart is "typically" chelonian with an internal anatomy "much like" that of the green sea turtle (O’Donoghue, 1918). Leatherback turtles are huge, with adults weighing hundreds of kilograms and even approaching a ton (Eckert \& Luginbuhl, 1988; Georges \& Fossette, 2006), and if the heart has exceptional capacities, they are achieved with a large but typical chelonian heart. We did not identify any large interarterial foramens such as those reported from the specimen examined by Adams (1962). We found no foramen in the Canadian specimen, but in the Ballum specimen, we did find a potential foramen in the shared wall of the left and right aortas, but it was so small that it would not have qualified for surgical repair had it been a human atrial septal defect (Webb \& Gatzoulis, 2006).

Several anatomical traits of the leatherback heart resemble the typical chelonian heart and not those of monitors and pythons. The position of the coronary vessels on the ventricular surface are not consistent with ventricular septation as in monitors and pythons (or crocodylians) (Jensen et al., 2014). The leatherback ventricular apex is anchored by a gubernaculum cordis, which is a common trait in chelonians and lizards, but not in monitors and snakes (MacKinnon \& Heatwole 1981; Jensen et al., 2014). There is no vertical septum that extends to the vicinity of the atrioventricular valve. Compared to monitors and pythons, the muscular ridge is small. It has previously been stated that amongst sea turtles, leatherbacks have a particularly well-developed muscular ridge, but detailed information was not provided (Wyneken 2001, 2009). We have previously quantified the size of the muscular ridge in reptile ventricles from cross sections similar to Figure 5A (Jensen et al., 2014) and we find the Ballum specimen to a have a typical rather than enlarged muscular ridge.

A particularly well-developed trait in monitors and pythons is a bi-layered configuration of the muscular ridge and the bulbuslamelle (Jensen et al., 2014), best observed in a dilated ventricle. Since the Ballum heart was contracted, we could not determine whether the muscular ridge and the bulbuslamelle had a similar bi-layered configuration. In monitors and pythons, there are also cushions of mesenchymal tissue, where the muscular ridge and the bulbuslamelle abut each other (Jensen et al., 2010b; Hanemaaijer et al., 2019). We did not observe similar cushions in the leatherback hearts, but the absence of evidence is obviously not solid evidence of absence. 
Our description of a typical chelonian heart in the leatherbacks strongly indicate a considerable capacity for cardiac shunting and a lack of ventricular pressure separation. Other chelonians have large cardiac right-to-left shunts during diving (i.e. where oxygen-poor venous blood entering the ventricle from the right atrium is delivered to the aortas (e.g. Wang et al., 1997; Hicks, 1998). It is possible that leatherbacks also have large right-to-left cardiac shunt when diving, although the functional role of this shunt pattern remains to be established in diving reptiles (Hicks and Wang, 2012; Burggren et al., 2020). Cardiac right-to-left shunts lead to reductions in the arterial oxygen levels (i.e. both the partial pressure of oxygen and the oxygen concentration) and it has therefore been argued that functional division of the ventricle, as seen in monitors and pythons, provides for more efficient oxygen delivery and would be required for the ability to maintain the high aerobic metabolism needed for sustained physical activity. The leatherback turtle has some degree of endothermy and performs long migrations, so it would be expected that this species, in particular, could have evolved a more divided ventricle. Our present study shows that this is not the case. As an alternative explanation, it is possible that the leatherback fuel the high aerobic metabolism during migration by virtue of a large stroke volume provided by the very large heart. The relative large size of the heart has to be confirmed in additional specimens and the inferred large stroke volume would have to be validated by measurement of arterial blood flows in live animals.

Most chelonian hearts have a cartilage or bone deposit where the muscular ridge merges with the truncus arteriosus (O'Donoghue, 1918, Lopez et al., 2003; Poelmann et al., 2017). We saw a patch of different signal intensity on the MRI at this location, but we could not ascertain that this was indeed cartilage on the basis of the CT. We also saw straight lines in the ventricular cavities, which obscured the region under the atrioventricular valve where strands of connective tissue have been reported in several chelonian species (Greil, 1903; Acolat, 1943; Jensen et al., 2014). Such fine strands are not only easily missed, but they are perhaps lost 272 during dissection when coagulated blood is removed from the ventricle. Adams (1962) 273 describes numerous dimples on the luminal side of the arterial walls of his single specimen. We did not detect such dimples in either the Ballum or Canadian hearts.

In conclusion, despite leatherback turtles exhibiting adaptations to their unusual lifestyle, such as a high hematocrit (Lutcavage et al., 1990), the heart itself is typically chelonian in most regards. The only exceptional cardiovascular trait may be the relatively large heart that may provide for large stroke volumes. 


\section{Acknowledgements}

This work was supported by the Lundbeck Foundation (Grant\# R324-2019-1470). A special thanks to Charlotte Bie Thøstesen for inviting TW and BJ to join the dissection of the Ballum leatherback and also thanks to the other members of the dissection team; Aage Kristian Olsen Alstrup, Daniel Klingberg Johansson, Hans Viborg Kristensen, Michael Paul Jensen, and Tim Kåre Jensen. Rasmus Buchanan and Jaco Hagoort gave technical assistance.

\section{Data Availability Statement}

The data that support the findings of this study are available from the corresponding author upon reasonable request.

\section{References}

Acolat, L., 1943. Contribution à l'anatomie comparée du cæur, et en particulier du ventricule, chez les batraciens et chez les reptiles. Thèses a la Faculté des Sciences de Nancy. Imprimerie de l'Est, Besançon.

Adams, W.E., 1962. The carotid sinus-carotid body problem in the Chelonia (with a note on a foramen of Panizza in Dermochelys). Archives internationales de pharmacodynamie et de therapie, 139, pp.28-37.

Brücke, E., 1852. Beiträge zur vergleichenden Anatomie und Physiologie des GefässSystemes. Denkschriften der Kaiserliche Akademie der Wissenschaften-MathematischNaturwissenschaftliche Classe 3, 335-367 (with Taf. XVIII-XXIII).

Burggren, W. \& Johansen, K., 1982. Ventricular haemodynamics in the monitor lizard Varanus exanthematicus: pulmonary and systemic pressure separation. Journal of Experimental Biology 96, 343-354.

Burggren, W., Filogonio, R. and Wang, T., 2020. Cardiovascular shunting in vertebrates: a practical integration of competing hypotheses. Biological Reviews, 95(2), 449-471.

de Bakker, B.S., de Jong, K.H., Hagoort, J., de Bree, K., Besselink, C.T., de Kanter, F.E., Veldhuis, T., Bais, B., Schildmeijer, R., Ruijter, J.M. and Oostra, R.J., 2016. An interactive three-dimensional digital atlas and quantitative database of human development. Science, 354(6315), p.aag0053.

Eckert, K.L. and Luginbuhl, C., 1988. Death of a giant. Marine Turtle Newsletter, 43, 2-3.

Georges, J.Y. and Fossette, S., 2006. Estimating body mass in leatherback turtles Dermochelys coriacea. Marine Ecology Progress Series, 318, 255-262. 
Greil, A., 1903. Beiträge zur vergleichenden Anatomie und Entwicklungsgeschichte des Herzens und des Truncus arteriosus der Wirbelthiere. Morphologisches Jahrbuch 31, $123-210$.

Grigg, G., Nowack, J., Bicudo, J.E.P.W., Bal, N.C., Woodward, H.N. and Seymour, R.S., 2021. Whole-body endothermy: ancient, homologous and widespread among the ancestors of mammals, birds and crocodylians. Biological Reviews. https://doi.org/10.1111/brv.12822

Hanemaaijer, J., Gregorovicova, M., Nielsen, J.M., Moorman, A.F.M., Wang, T., Planken, R.N., Christoffels, V.M., Sedmera, D. and Jensen, B., 2019. Identification of the building blocks of ventricular septation in monitor lizards (Varanidae). Development, 146(14), p.dev177121.

Hicks, J. W., 1998. Cardiac shunting in reptiles: mechanisms, regulation and physiological functions. In Biology of the Reptilia, Volume 19, Morphology G: The Visceral Organs (eds C. Gans and A. S. Gaunt), pp. 425-483. Society for the Study of Amphibians and Reptiles, Ithaca, New York.

Hicks, J.W. and Wang, T., 2012. The functional significance of the reptilian heart: new insights into an old question. In Ontogeny and Phylogeny of the Vertebrate Heart (pp. 207-227). Springer, New York, NY.

James, M.C. and Mrosovsky, N., 2004. Body temperatures of leatherback turtles (Dermochelys coriacea) in temperate waters off Nova Scotia, Canada. Canadian Journal of Zoology, 82(8), pp.1302-1306.

Jensen, B., Nielsen, J.M., Axelsson, M., Pedersen, M., Löfman, C. and Wang, T., 2010a. How the python heart separates pulmonary and systemic blood pressures and blood flows. Journal of Experimental Biology, 213(10), pp.1611-1617.

Jensen, B., Nyengaard, J.R., Pedersen, M. and Wang, T., 2010b. Anatomy of the python heart. Anatomical Science International, 85(4), pp.194-203.

Jensen, B., Moorman, A.F. and Wang, T., 2014. Structure and function of the hearts of lizards and snakes. Biological Reviews, 89(2), pp.302-336.

Jensen, B., Vesterskov, S., Boukens, B.J., Nielsen, J.M., Moorman, A.F., Christoffels, V.M. and Wang, T., 2017. Morpho-functional characterization of the systemic venous pole of the reptile heart. Scientific Reports, 7(1), pp.1-12.

Jensen, B. and Christoffels, V.M., 2020. Reptiles as a model system to study heart development. Cold Spring Harbor Perspectives in Biology, 12(5), p.a037226. 
Johansen, K., 1959. Circulation in the three-chambered snake heart. Circulation Research 7, $828-832$.

Kardong, K. V., 2006. Vertebrates: Comparative anatomy, function, evolution. Boston, MA: McGraw-Hill.

Katano, W., Moriyama, Y., Takeuchi, J.K. and Koshiba-Takeuchi, K., 2019. Cardiac septation in heart development and evolution. Development, Growth \& Differentiation, 61(1), pp.114-123.

López, D., Durán, A. C., de Andrés, A. V., Guerrero, A., Blasco, M. \& Sans-Coma, V., 2003. Formation of cartilage in the heart of the Spanish terrapin, Mauremys leprosa (Reptilia, Chelonia). Journal of Morphology, 258, 97-105.

Lovegrove, B.G., 2017. A phenology of the evolution of endothermy in birds and mammals. Biological Reviews, 92(2), pp.1213-1240.

Lutcavage, M.E., Bushnell, P.G. and Jones, D.R., 1990. Oxygen transport in the leatherback sea turtle Dermochelys coriacea. Physiological Zoology, 63(5), pp.1012-1024.

MacKinnon, M. R. \& Heatwole, H., 1981. Comparative cardiac anatomy of the reptilia. IV. The coronary arterial circulation. Journal of Morphology, 170, 1-27.

O'Donoghue, C.H., 1918. The heart of the leathery turtle, Dermochelys (Sphargis) coriacea. With a note on the septum ventriculorum in the Reptilia. Journal of Anatomy, 52(4), 467480.

Paladino, F.V., O’Connor, M.P., and Spotila, J.R., 1990. Metabolism of leatherback turtles, gigantothermy, and thermoregulation of dinosaurs. Nature (Lond.), 344, 858-860.

Poelmann, R. E., Groot, A. C., Vicente-Steijn, R., Wisse, L. J., Bartelings,M. M., Everts, S., ... Richardson, M. K., 2014. Evolution and development of ventricular septation in the amniote heart. PLoS One, 9(9), e106569.

Poelmann, R.E., Gittenberger-de Groot, A.C., Biermans, M.W., Dolfing, A.I., Jagessar, A., van Hattum, S., Hoogenboom, A., Wisse, L.J., Vicente-Steijn, R., de Bakker, M.A. and Vonk, F.J., 2017. Outflow tract septation and the aortic arch system in reptiles: lessons for understanding the mammalian heart. Evodevo, 8(1), 1-17.

Poelmann, R.E. and Gittenberger-de Groot, A.C., 2019. Development and evolution of the metazoan heart. Developmental Dynamics, 248(8), 634-656.

Quick, D.E. and Ruben, J.A., 2009. Cardio-pulmonary anatomy in theropod dinosaurs: Implications from extant archosaurs. Journal of Morphology, 270(10), 1232-1246.

Valentinuzzi, M. E. \& Hoff, H. E., 1972. The sinus venosus-atrial Wenckebach-Luciani phenomenon. Journal of Electrocardiology, 5, 1-14. 
380

381

382

383

Wang, T., Altimiras, J., Klein, W. \& Axelsson, M., 2003. Ventricular haemodynamics in Python molurus: separation of pulmonary and systemic pressures. Journal of Experimental Biology, 206, 4241-4245.

Wang, T., Krosniunas, E.H. and Hicks, J.W., 1997. The role of cardiac shunts in the regulation of arterial blood gases. American Zoologist, 37(1), 12-22.

Webb, G., Heatwole, H. and De Bavay, J., 1971. Comparative cardiac anatomy of the Reptilia. I. The chambers and septa of the varanid ventricle. Journal of Morphology, 134(3), 335350 .

Webb, G.J.W., 1979. Comparative cardiac anatomy of the reptilia. III. The heart of crocodilians and an hypothesis on the completion of the interventricular septum of crocodilians and birds. Journal of Morphology, 161, 221-240.

Webb, G. and Gatzoulis, M.A., 2006. Atrial septal defects in the adult: recent progress and overview. Circulation, 114(15), 1645-1653.

White, F. N., 1968. Functional anatomy of the heart of reptiles. American Zoologist, 8, 211219.

Wyneken, J., 2001. The Anatomy of Sea Turtles. U.S. Department of Commerce NOAA Technical Memorandum NMFS-SEFSC-470, 1-172.

Wyneken, J., 2009. Normal reptile heart morphology and function. Veterinary Clinics of North America: Exotic Animal Practice, 12, 51-63. 

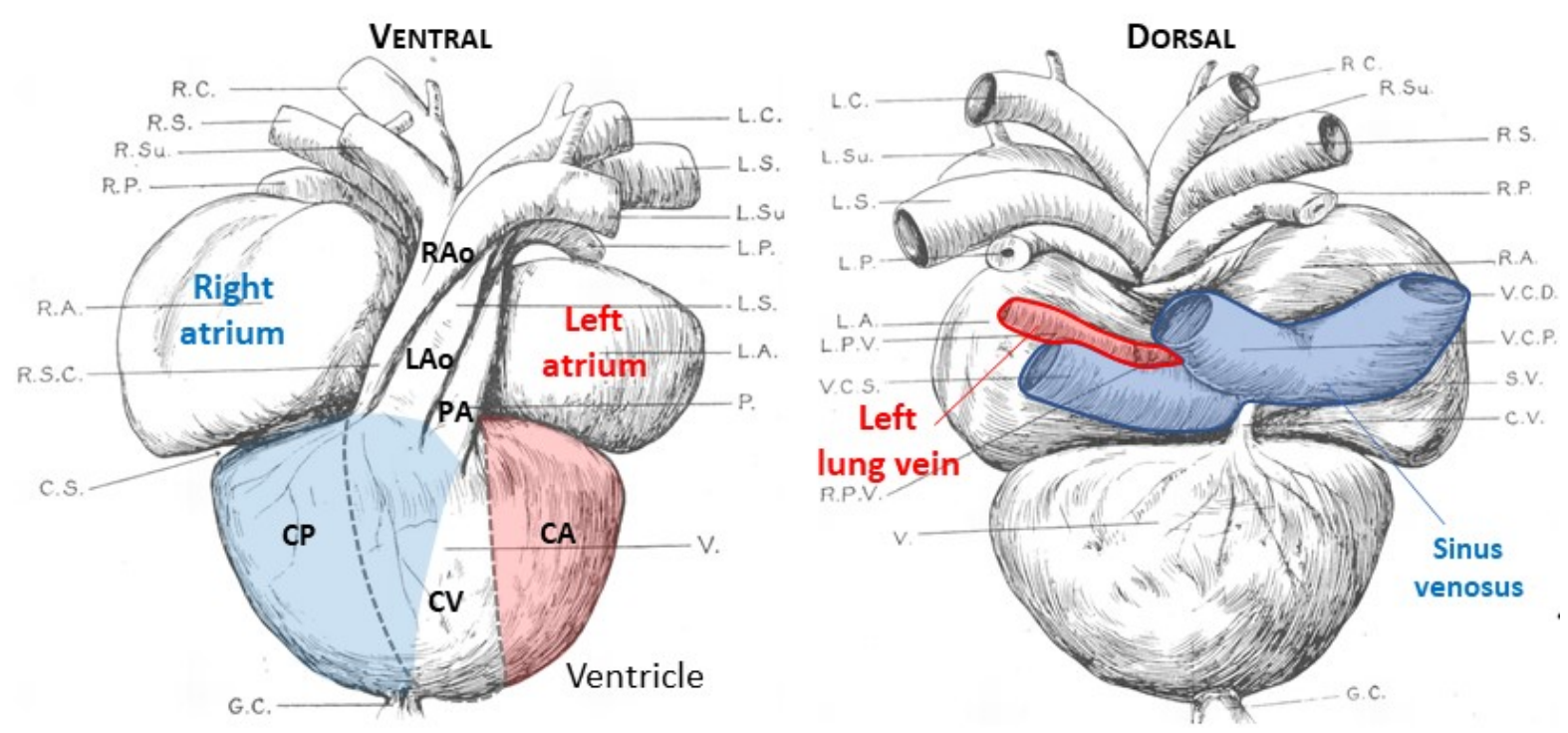

400

Figure 1. External view of the heart of a leatherback turtle. In the ventricle, the red color indicates the cavum arteriosum (CA) and blue indicates the cavum pulmonale (CP). Notice CP is partly ventral to the cavum venosum $(\mathrm{CV})$, which is indicated by the blue area within the dashed-line perimeter of the CV. LAo, left aorta; L.P.V. (shaded red) is left lung vein; PA; pulmonary artery; RAo, right aorta. Adapted from O'Donoghue (1918). The original abbreviations are; C.S., coronary sulcus; C.V., coronary vein; G.C., gubernaculum cordis;

407 L.A., left auricle; L.C., left carotid artery; L.P., left pulmonary artery; L.P.V., left pulmonary vein; L.S., left systemic arch; L.Su., left subclavian artery; P., pulmonary arch; P.V., pulmonary vein; R.A., right auricle; RA., right carotid artery; R.P., right pulmonary artery; R.P.V., right

410 pulmonary vein; R.S., right systemic artery; R.S.C., right systemico-carotid trunk; R.Su., right 411 subclavian artery; S.V., sinus venosus; V., ventricle; V. C.D., right pre-caval vein; V.C.P., post. caval vein; V.C.S., left pre-caval vein. 

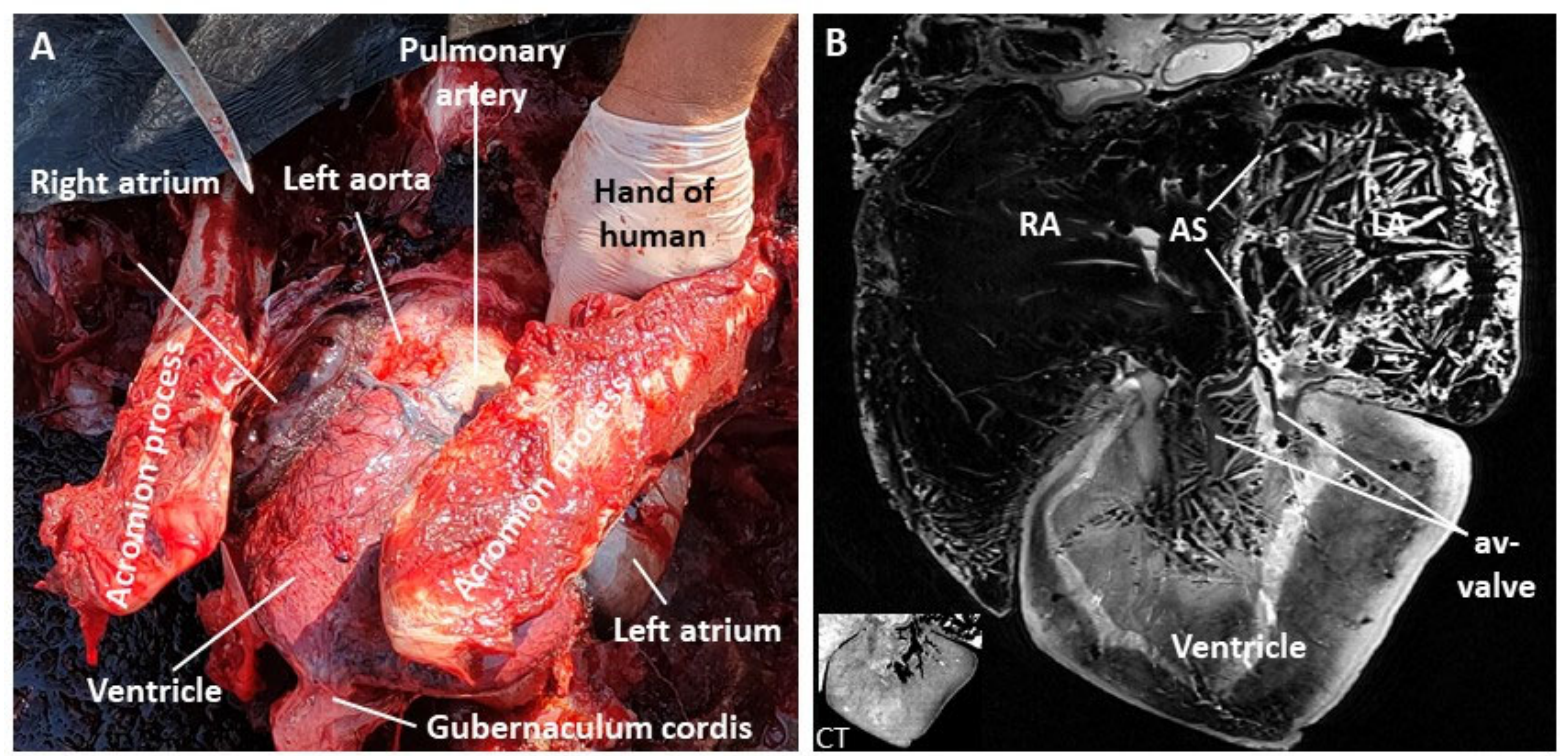

C Leatherback

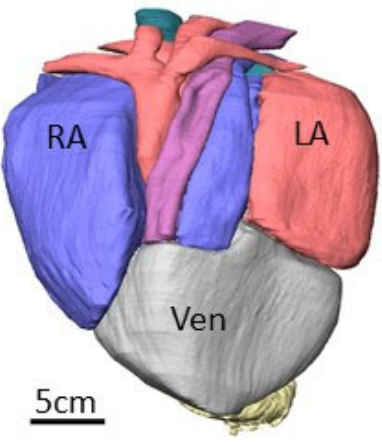

TORTOISE

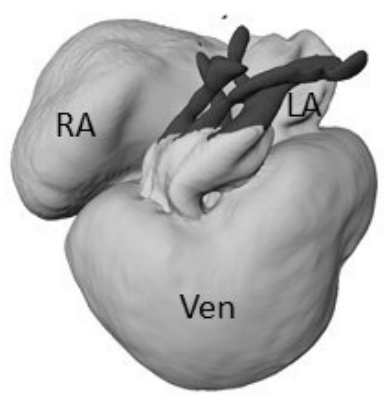

MONITOR

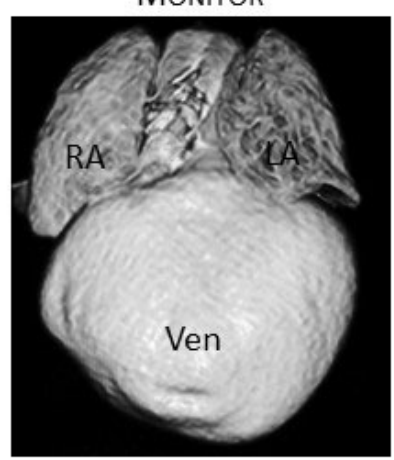

PYTHON

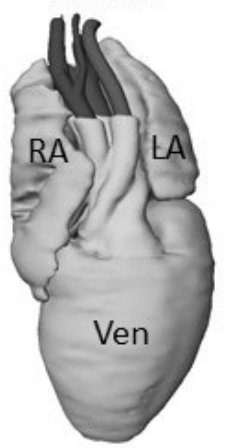

Figure 2. Heart of the Ballum turtle. A. Caudal-ventral in-situ view of the heart of the Ballum turtle. B. Example of MR-generated image of the heart. In the ventricle several bands are seen,

416 but these are likely artefacts because the bands are not detected on CT (insert on the bottom

417 left). C. Reconstruction of the Ballum turtle heart, next to reconstructions based on MRI of the

418 hearts of the red-footed tortoise, the Asian water monitor, and the Burmese python. 

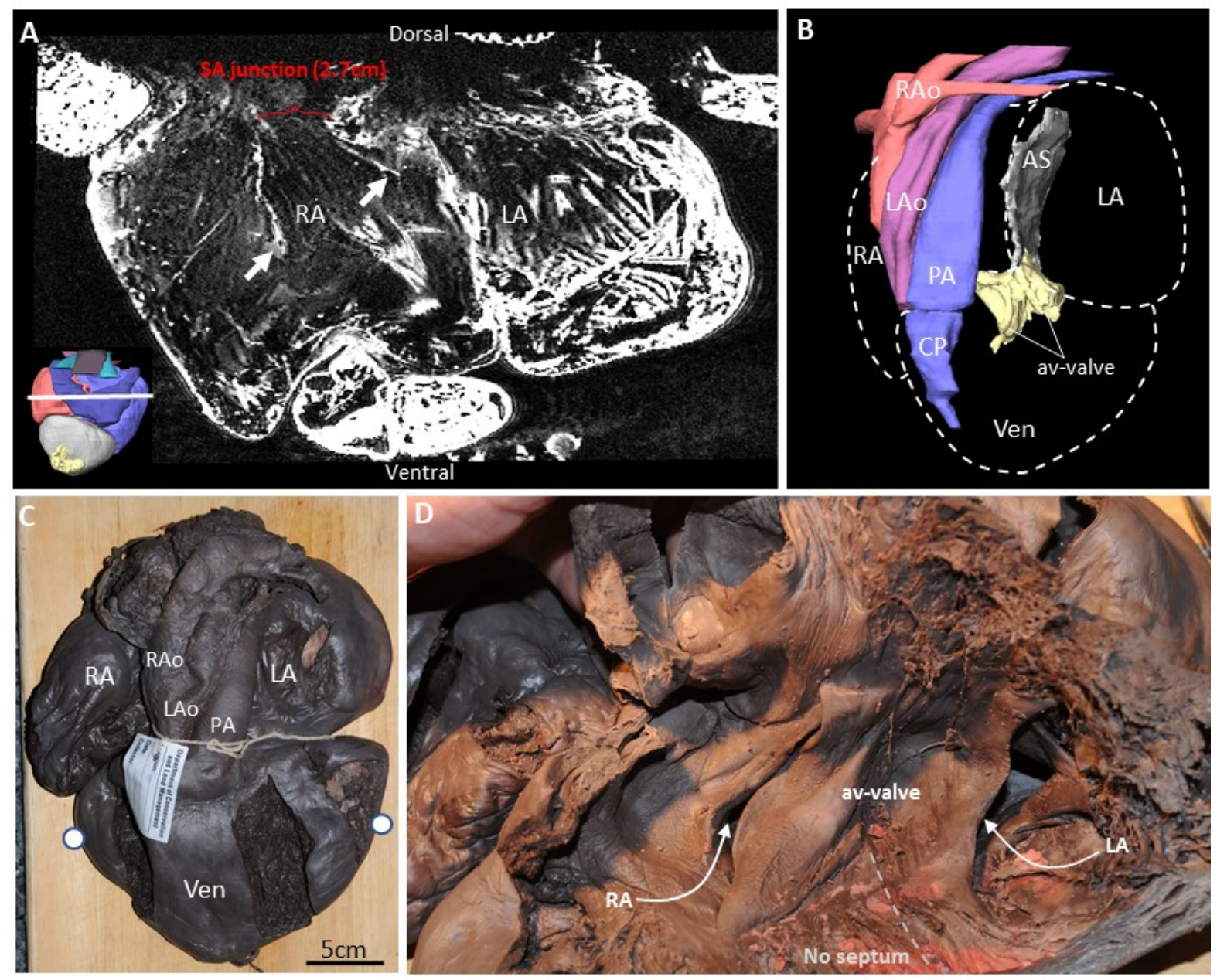

420 Figure 3. Chamber junction valves. A. The atria in the transverse plane, showing the two

421 leaflets (white arrows) of the sinuatrial valve at the base of which is the sinuatrial junction

422 which at this location $2.7 \mathrm{~cm}$ wide. In the insert on the bottom-left, the section plane is indicated

423 by a white line. B. Reconstruction of the atrioventricular valve (av-valve) showing that it is 424 connected to the atrial septum (AS), and it is at some distance from the cavum pulmonale (CP) 425 which leads to the pulmonary artery (PA). C. Ventral view of the Canadian heart. The two 426 white dots on the ventricle (Ven) indicates the plane of cutting used to produce the view in D.

427 D. When the apical part is removed and the ventral part of the ventricle is lifted, the av-valve 428 is exposed showing two large leaflets, one for each of the atrial inflows. A substantial 429 communication is possible between the left and right side of the ventricle because there is no 430 ventricular septum immediately below the av-valve, leading some authors to consider this part 431 as a single chamber, the cavum dorsale. LA, left atrium; LAo, left aorta; RA, right atrium; RAo, right aorta. 

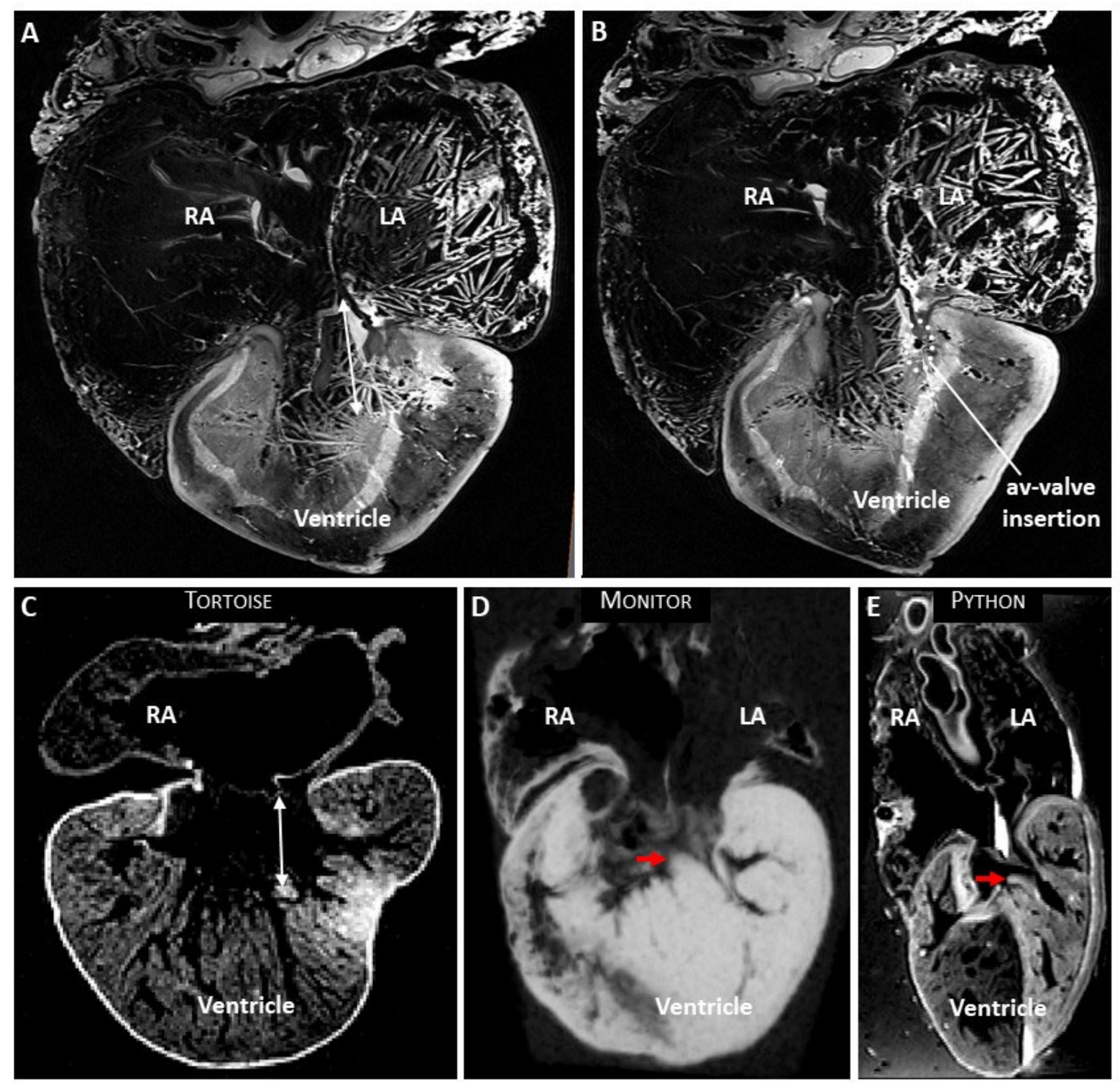

433

434 Figure 4. The vertical septum of the ventricle. A. In the leatherback ventricle, a large gap

435 (double-headed arrow) is found between the ventricular muscle and the point where the two

436 leaflets of the av-valve connects to the atrial septum. The shown image is approximately in the

437 horizontal plane. B. Ventrally (and dorsally) the av-valve is inserted in ventricular muscle, an

438 example of this is indicated with the dashed ovale. C. The tortoise also has a large gap between

439 the ventricular muscle and the av-valve. D-E. In the monitor and python, the vertical septum

440 (red arrow) almost makes contact with the av-valve. LA, left atrium; RA, right atrium. 

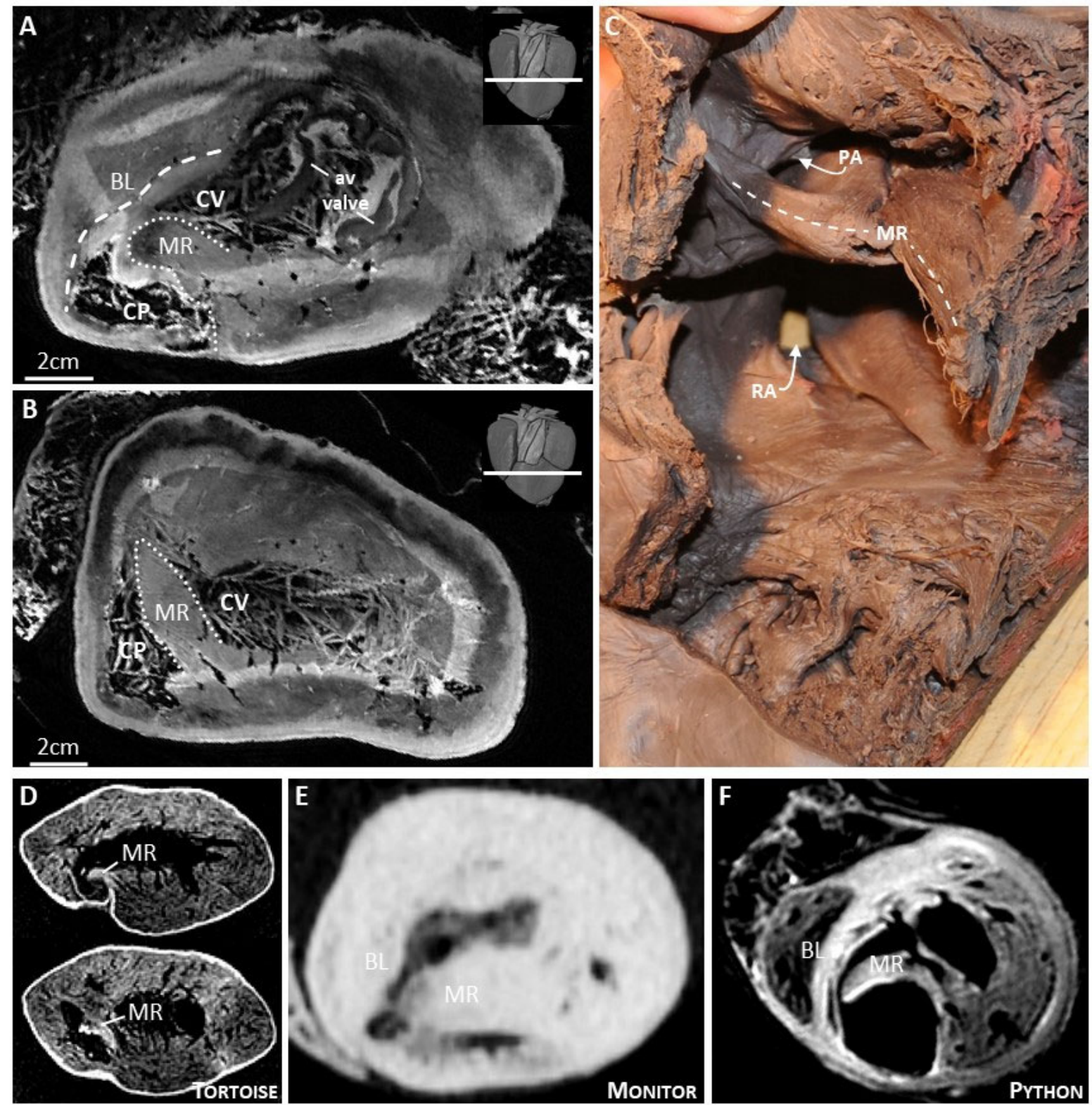

441

442 Figure 5. The muscular ridge of the ventricle. A. In the leatherback ventricle, the most

443 pronounced septal structure is the muscular ridge (MR) opposite which is the bulbuslamelle

444 (BL). These two structures mark the boundary between the cavum venosum (CV) and cavum 445 pulmonale (CP). In the insert on the top-right, the section plane is indicated by a white line. B.

446 The free edge of the muscular ridge has a spiral course and towards the apex it merges with 447 myocardium of the dorsal-right wall. C. Muscular ridge of the Canadian heart, notice the large 448 space between the free edge of the muscular ridge and the opposite wall. D. Muscular ridge of 449 the tortoise. E. The muscular ridge of the monitor is exceptionally large. F. In the python, the 450 muscular ridge and the bulbuslamelle are both exceptionally well-developed. 

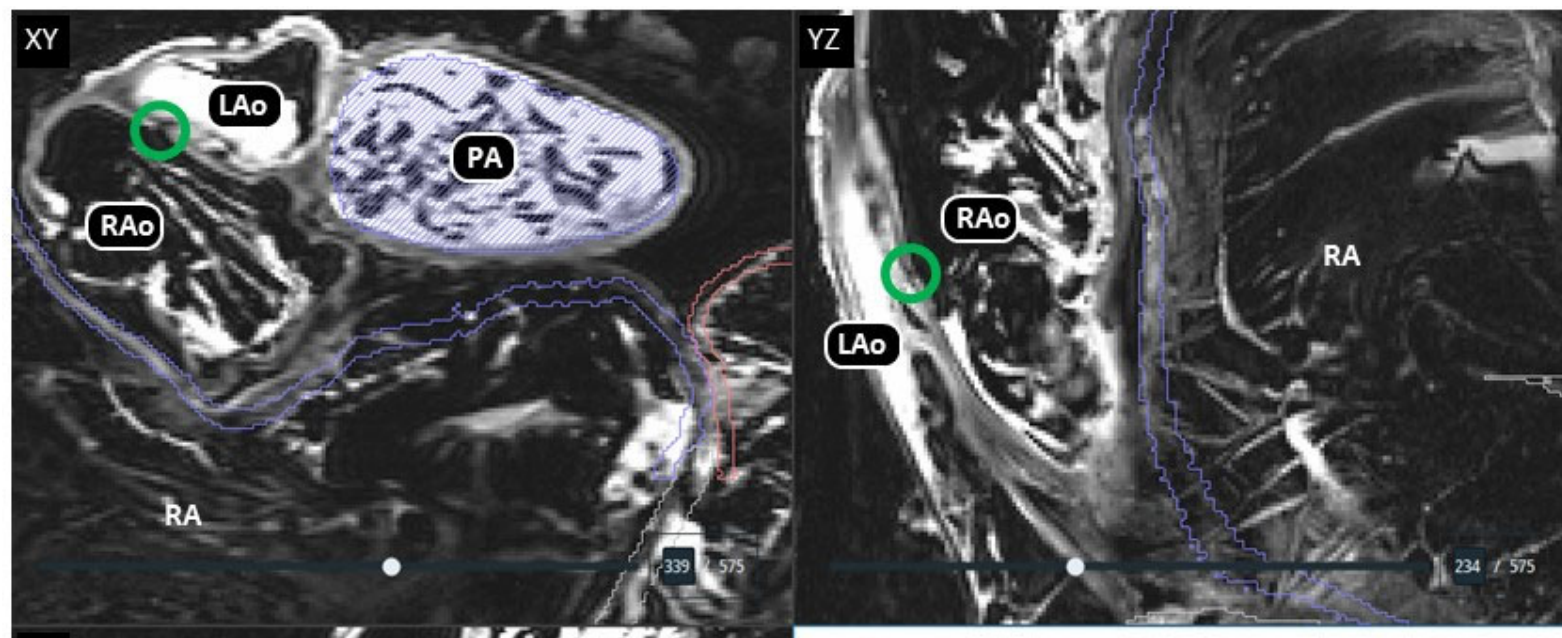

$X Z$
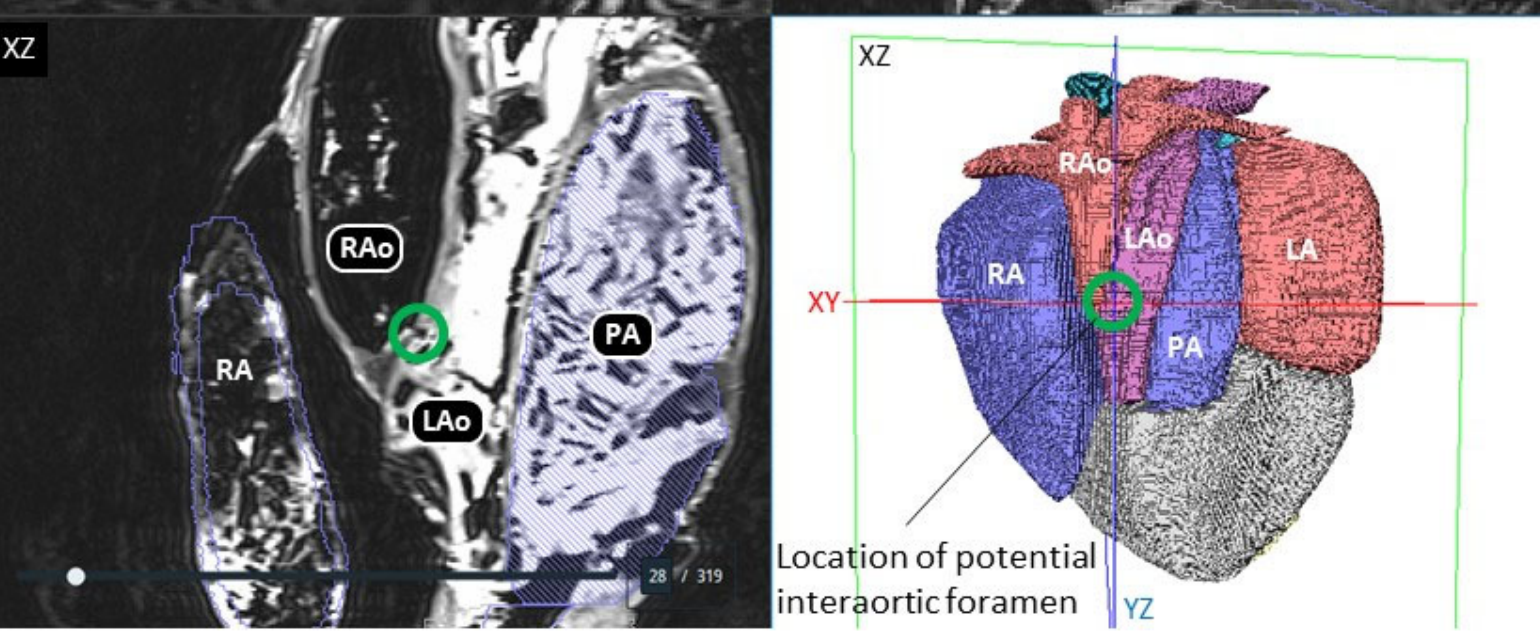

Figure 6. No pronounced interarterial foramens. In the Ballum turtle, we investigated all images in the three orthogonal planes (XY, YZ, XZ) but we did find such foramens as described by Adams (1962). A potential but very small foramen (green ring) was found at approximately 